\title{
Correlation analysis of the population and energy_the coexistence of promotion and inhibition
}

\author{
Wang Lingxiao, a , Chen Yufang ${ }^{2, b}$, Zhu Weifeng ${ }^{3, c}$ \\ ${ }^{1}$ School of Energy and Power Engineering, Jiangsu University, No. 301 Xuefu Road, Zhenjiang \\ City,212000, China \\ ${ }^{2}$ School of Computer Science and Telecommunication Engineering, Jiangsu University, No. 301 \\ Xuefu Road, Zhenjiang City,212000, China \\ ${ }^{3}$ School of Energy and Power Engineering, Jiangsu University, No. 301 Xuefu Road, Zhenjiang \\ City,212000, China \\ a18852850785@163.com, ${ }^{\mathrm{b}} \underline{18852857787 @ 163 . c o m},{ }^{\mathrm{c}}$ 18852852292@163.com
}

Keywords: Energy; Population; Economy; Promotion; Inhibition

Abstract. The energy innovation has brought about an exponential increase of population each time, meanwhile, population growth brings greater energy demand. Hence how to maintain a balanced relation between energy production-consumption and population is of great importance. This paper highlights the relations between China's energy development and population growth, after investigating and analyzing the direct relation between energy development and population growth and the indirect effects of the economy on population and energy, concluding that both the relations of promotion and restriction exist between energy and population. And offer reasonable proposals from aspects of international energy cooperation, industrial structure optimization, exploitation and utilization of energy resource and population structure optimization.

\section{Introduction}

Energy development accompanies the progress and development of human society, in some ways, it is the discovery and use of energy that can help humanity get rid of the savage condition and evolve the intelligent brain step by step. Behind each of population explosion, there was always the exploration and utilization of new energy provided strong pushing power. History has demonstrated that the population scale has to accommodate both the level of economic development and energy capacity, nevertheless the population that energy capacity can bear is limited and once it is overloaded the backdraft will effect on economic development and population growth. So that, understanding China's current energy situation and law of population development under special conditions is of great importance.

\section{China's population and energy resources situation}

\section{Energy resources}

China is a vast country, land area of 9.6 million square kilometers, sea area of 3 million square kilometers, having diversified geological conditions, abundant in energy resources. The reserves of conventional energy such as coal, petroleum, gas, waterpower is among top of world. The latest reservation data published by Ministry of Land and Resources of China reveals that up to 2015, coal resource is of 1566.31 billion tons, petroleum resource is of 3.5 billion tons, natural gas resource is of 5194 billion cubic meters, shale gas is of 130 billion cubic meters, water power reserves equivalent to annual electricity generation of 676 million $\mathrm{kW} \cdot \mathrm{h}$. (1) Except of these, ample energy resources including wind energy, solar energy and nuclear energy are also available in China. The great number of energy resource reserves means under the development of economy, energy could not only provide strong power for economic development, but also guard the development of population. 


\section{Population}

China has a population of 1.38 billion until 2015, account for $20 \%$ of the world population, undoubtedly the top worldwide. Since the founding of new China, the population increased about 5400 million in less than 70 years, it never happened with such astonishing velocity and amount of increase throughout the history of humanity development. Enormous population comes with considerable bonus and challenges. With China gradually steps into "new normal" completely, the total fertility rate comes to the lower level, and the troubles of gender imbalance, ageing of population and contradiction among population size, energy and environment have become increasingly prominent.

\section{The mutual promotion between energy and population}

Since the Reform and Opening-up, China's energy production has been developing rapidly. In 1978, the total national energy production is 627.7 million tons (standard coal), the total national energy consumption is 571.4 million tons (standard coal); in 2000, the total national energy productions are 1350.5 million tons (standard coal), the total national energy consumptions are 1469.6 million tons (standard coal), 2.2 times and 2.6 times respectively of 1978. In the course of the 22 years, the total population increment is 3000 million tons, annually increased 14 million on average. Additionally, the average annual gross domestic product (GDP) growth rate is $16.2 \%$, the rate of per capita disposable income growth is $14.1 \%$. 2) It can be seen that energy development is critical for economic development and humanity growth. As we know there are various kinds of energy, from the table below we can see the share of different energy in certain year's total energy production clearly. Before 2000 , coal had been in a steady risen trend, but after 2000 it maintains at $77 \%$, it matches the image that China is a large country in coal's production and consumption. On the one hand, the proportion of crude oil was declined year after year, but meanwhile, new types of energy such as natural gas, nuclear, wind power and hydroelectric power, became more and more important. This important change not only fits the mainstream trend of energy development, but also reflects the achievements that China did in improving the energy structure; meanwhile, we can see with the rapid development of energy, the total population was also in a rapid growth, from 1980 to 1985, only in 6 years, population increased by nearly 100 million, such a large development has no peer even in the human history. The positive effect that energy has on population growth is needless to say. 


\begin{tabular}{|c|c|c|c|c|c|c|c|c|}
\hline$k_{2}$ & 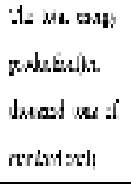 & 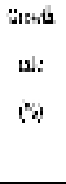 & $\begin{array}{l}6 a b \\
\because y \\
m 1\end{array}$ & $\begin{array}{l}\text { Ėitu } 1 \text {. } \\
\therefore 14\end{array}$ & 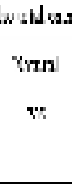 & 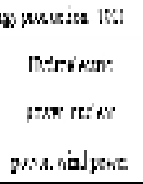 & 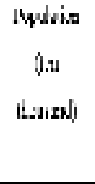 & 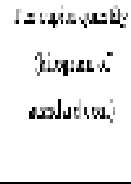 \\
\hline 19 & וציו & $\mathrm{A}$ & $\because 1$ & $n$ & 90 & , & W: & M:I \\
\hline 150 & sme & Is & $1: 1$ & $n s$ & 1 & 1 & Xiv & BM: \\
\hline 14 & жи & W; & 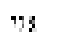 & $\pi 4$ & ; & $i$ & แח & sas: \\
\hline $1 \%$ & Ims & " & 12 & ; & ; & 1 & $1 \mathrm{~m}$ & wos \\
\hline$m$ & 1204 & $H$ & $n$ & 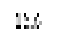 & b & $0 !$ & ובL"ב1 & woss \\
\hline Mot & Bs:t: & in & $y:$ & $\therefore$ & .r & $a s$ & :He:4: & wow \\
\hline$m$ & i2v. & st: & 268 & :. & : & it & $3: B$ & $|\omega x\rangle$ \\
\hline No & 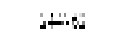 & 4 & $\therefore A$ & HL & it & is & 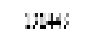 & trus \\
\hline$a$ & 要 & 111 & ',y & $1: 1$ & ir & I & iry & Is:A; \\
\hline$m$ & ; & $\therefore$ & $" s$ & I" & 1। & $B$ & $m$ & $|A| i \mid$ \\
\hline $\mathrm{ms}$ & WIV & 11 & 1.1 & 6 & 1 & $x_{1}$ & 1441.1 & $w$ \\
\hline Ats & :1.1.14 & $!$ & $a b$ & 18 & 1. & $\because 1$ & .3121 & 210 \\
\hline ג.. & : $:(1)$ & is & $\because \therefore$ & 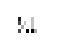 & 1. & X: & $s \mid w s$ & 2500 \\
\hline$m !$ & :sti: & : & $: 8$ & 3.9 & 1.1 & $: . .1$ & $3: n$ & l to:s \\
\hline
\end{tabular}

On the other hand, the ever-increasing population and gradually expanding population scale comes with large amount of labors and talented persons, which contributes a lot for the firm foundation of national economy and accumulation of wealth. As is known to all, population is closely relevant to energy scale, level of income and output value. Take total energy production and consumption, GNI and per capita of GDP as examples, it can be easily recognized that with the continued expansion of humanity scale, total energy production and consumption, GNI and per capita GDP have also been promoted. Among which, energy scale magnified about 38\%, and both the GNI and per capital GDP multiplied about 2.5 times. From the diagrams, we can directly understand the development of various indexes from 2007 to 2015, separating them can show their evolution trend better.

Table 2. The development of energy, population and GDP in recent 5 years ${ }^{(2)}$

\begin{tabular}{ccccccc}
\hline Item & Unit & 2007 & 2009 & 2011 & 2013 & 2015 \\
\hline $\begin{array}{c}\text { Population } \\
\text { The total energy }\end{array}$ & $\begin{array}{c}\text { Ten thousand } \\
\text { production }\end{array}$ & 132129 & 133450 & 134735 & 136072 & 137462 \\
& $\begin{array}{c}\text { Ten thousand } \\
\text { tons of } \\
\text { gtandard coal }\end{array}$ & 264173 & 286092 & 340177 & 358784 & 362000 \\
Rate of increase & $\%$ & 15.3 & 8.3 & 18.9 & 5.5 & 0.9 \\
$\begin{array}{c}\text { The total energy } \\
\text { consumption }\end{array}$ & $\begin{array}{c}\text { Ten thousand } \\
\text { tons of }\end{array}$ & 311442 & 336126 & 387043 & 416913 & 430000 \\
& standard coal & & & & & \\
Rate of increase & $\%$ & 19.2 & 8 & 15 & 7.7 & 3.1 \\
Nation income & Billion RMB & 27084.4 & 34849.8 & 48475.3 & 59042.2 & 68263.5 \\
Per capita GDP & RMB & 20505 & 26222 & 36403 & 43852 & 49992 \\
\hline
\end{tabular}




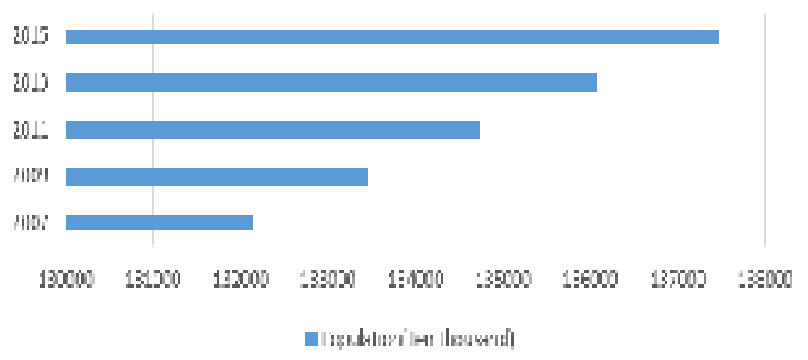

Fig. 1. China's grow trend of population

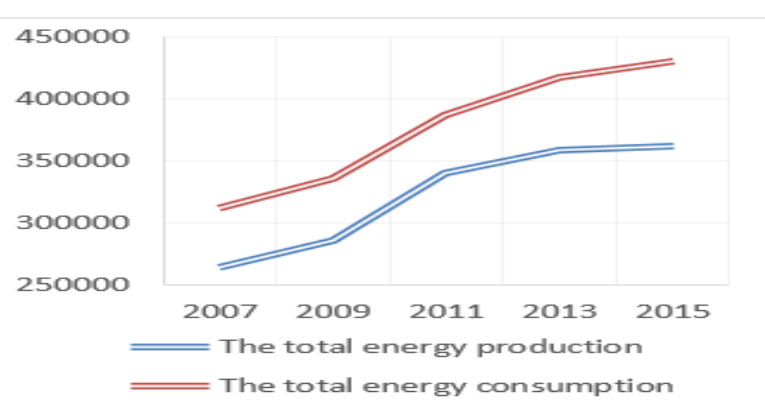

Fig. 2. China's grow trend of energy

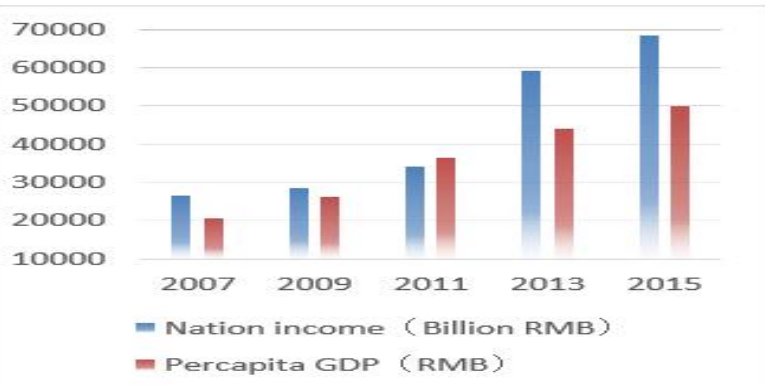

Fig. 3. China's grow trend of national income and per capita GDP

\section{The restrictive relation between energy development and population}

However, we should be clearly aware of the relation between energy and population, it's not just in positive circulation. Basing on huge population size and the gradually improvement of economy, science and technology, China's demand for energy will be larger, which means large challenges are getting in the way of China's energy development. Even if both of China's total energy production and consumption are among the highest of the world, because of the enormous population, the level of per capita in China is just at the middle level worldwide. Table 3 represents the per capita energy consumption of some countries and regions since the beginning of the 21 st century. On the one hand, we can see that the United States, Russia, Canada, all of these typical developed countries' per capita energy consumption is always at the front ranks of world. But the sum of the total population of these three countries isn't up to half of China's population. On the other hand, China and India, the two largest populous nations in the world, although the total energy production and consumption are considerable, the per capita energy consumption level is relatively low in the world. In diagram4, the proportion of each country's per capital energy consumption in world energy territory is stick out a mile, China is just a tiny part of it. So that we can see when the scale of population and energy is out of balance, population will have quite restrictive effects upon energy. The reason is the scale of energy itself will be hard to support enormous pressure and burden triggered by the huge population, as a matter of result the development will be inhibited. Meanwhile, because of the limitation of population that energy can feed as well as the short of sufficient power in face of enormous population, the 
inhibition of population development is reasonable. From what has been discussed above, we can draw an opposite conclusion that the relation between energy and population, sometimes inhibits each other's development. The contradiction between energy development and population growth, early to 1970s had been noticed by western scholars.

Table 3 ( Tons of standard coal/People)

\begin{tabular}{cccccccc}
\hline Country/Region & 1990 & 2000 & 2005 & 2009 & 2010 & 2011 & Average \\
\hline World(Average) & 2.39 & 2.36 & 2.53 & 2.57 & 2.68 & 2.68 & 2.54 \\
OECD Country & 6.19 & 6.73 & 6.78 & 6.11 & 6.27 & 6.11 & 6.37 \\
U.S. & 10.94 & 11.50 & 11.27 & 10.05 & 10.21 & 10.03 & 10.67 \\
China & 0.87 & 1.15 & 1.81 & 2.30 & 2.43 & 2.59 & 1.86 \\
Russia & 8.50 & 6.03 & 6.50 & 6.51 & 7.07 & 7.36 & 7.0 \\
India & 0.53 & 0.64 & 0.70 & 0.84 & 0.84 & 0.84 & 0.73 \\
Japan & 5.08 & 5.84 & 5.91 & 5.30 & 5.57 & 5.16 & 5.48 \\
U.K. & 5.14 & 5.41 & 5.56 & 4.55 & 4.65 & 4.28 & 4.93 \\
Canada & 10.76 & 11.71 & 12.10 & 10.76 & 10.55 & 10.43 & 11.05 \\
South Africa & 3.81 & 3.71 & 3.86 & 4.17 & 4.07 & 3.99 & 3.94 \\
Brazil & 1.34 & 1.56 & 1.64 & 1.77 & 1.94 & 1.96 & 1.70 \\
\hline
\end{tabular}

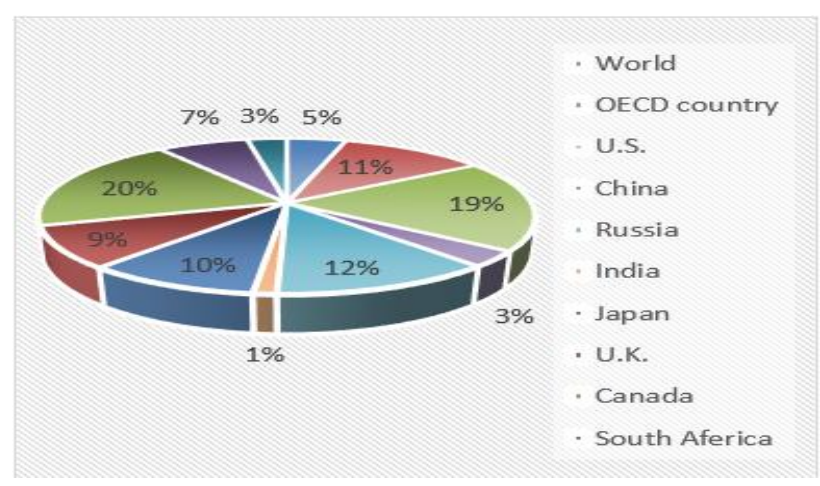

Fig. 4. Per capita energy consumption of some countries and regions

In 1972, an academic organization Club of Rome which is established by scholars focus on world's future and development published a research report called Limits to Growth, this report takes aim at making explanation to severe energy consumption and waste of resources issues causing by national population and rapid economic growth of Western. Growth Limit Theory, a new theory was proposed from this report, "If the growing trend of world's population, energy consumption, waste of resources, grain production and industrialization continue in accordance with this existing situation, then this planet's economic growth will reach a limit at some point of time in the next 100 years, and the most probably situation is the population and industrial capacity could happened with quite suddenly and uncontrolled recession or decline" . ${ }^{3}$ As for China, Limit of Growth has been reflected in the aspects of economy, population and energy. The financial tsunami broke out in 2008 isn't go away, even though China avoided direct impact of crisis relied on its special political system and the socialist market economic system, as an important part of world economy, the impact on China should not be underestimated. After China's economy achieved the fastest growth of the growth cycle in 2007, economic growth began to decline and exhibited signs of pacing down and gradually step into New Normal, the pulling power for world's economy has gradually to be weak. When it comes to population, whether the annual growing number or annual growth rate has decreased year by year, especially the average annual growing number has even dropped to millions. However, with the degree of aging population constantly deepening and demographic dividend gradually subsided, the 
future situation of China's population is not optimistic. As for energy, resource reserves' gap has also expanded because of large energy consumption and the contradiction between energy development and population growth, only in 2014 alone, Chinese domestic gas and petroleum can's meet the demand in next 31 years, oil gap was 15.5 times of domestic reserves in 2008, natural gas was 3.14 times of domestic reserves in 2008.

\section{Conclusion}

British economist Thomas Malthus's An Essay on the Principle of Population and the Club of Rome's Limits to Growth put forward views for future evolution of mankind. An Essay on the Principle of Population attaches the great importance to the restriction of food and other living materials on population (referred to as "Determining population with food"), and the Limits to Growth extended to the restriction of resources and environment on population. This paper further deducts to mutual determination of energy and population. The interaction between energy and population exists at all time, just the mode of action varies in different periods. At the beginning of evolution, due to the relatively small size of China's population, energy was abundant and easy available, energy supply was sufficient, which provided a powerful impetus for the healthy and rapid development of population. And the rapid growth of population derives a large amount of labor force and excellent technological personnel, demographic dividend effected on the promotion of energy's rapid development. However, with the development of evolution, "limits to growth" gradually emerged. Owing to the ever-increasing population, the maximum of population that energy can bear was broken through, which follows with a sharp drop in annual population growth rate and number, as well as deterioration of demographic structure. And because of the enormous population and unprecedented increment of energy demand, the burden that energy loaded was too heavy so that the limit threshold that sustained steady development of energy was worn out, as a result China has gradually expanded the gap of energy resources reserves.

\section{Rationalization proposals}

Energy and population, they can both inhibit or promote each other, which is so contradictory sometimes but objectively exists in the world. In order to weaken negative impact and enhancing promoting effect, I propose the following suggestions:

(1) Further expand international energy cooperation. Participating bilateral and multilateral cooperation in international energy actively, appropriate utilize foreign resource by national trade and participating in upstream exploration and production and so on. So that to have domestic energy supply get the necessary supplement, filling energy resource gap, having remission of China's low level of per capita energy consumption situation.

(2) In the context of the huge population base and low level of per capital energy, China should vigorously improve energy efficiency, working hard to reach the target of Energy Saving. In the short term, giving energy saving industrial research and development with a strong support, increasing utilization efficiency of coal, oil, gas and so on. Meanwhile, vigorously promoting energy saving awareness and ideas, establish valid laws and regulations concerning with energy saving, guiding people minimizing waste of energy in daily life and industrial production. In the long term, improving energy structure, vigorously develop new energy industry, converting the current structure which is highly dependent on oil and coal, developing green renewable energy including solar power, wind power, nuclear energy and so on.

(3) Improving and optimizing the structure of industry, making efforts on promoting circular economy and concept of sustainable development. Vigorously develop the tertiary industry, lower the proportion of the secondary industry in GDP. Restricting the development of industries which have large energy consumption and serious pollution, encouraging the development of high-tech industries, giving priority to information industry's development because it not only has low power consumption but also plays a great role in driving economic growth and living standards. So that constantly 
promoting status of high-tech industries in national economy, reducing energy consumption per unit of output. ${ }^{(1)}$

(4) Optimizing population structure, facilitating the relation between energy suppling and demanding to be reasonable. The state is composed of people, the optimum of population and demographic structure is crucial for national development, so the population problems not only result in detrimental effects on economic development, but also bring larger problems to energy development. In the present situation, China is facing relatively difficult problems from ageing of population, low fertility rate, gender proportion and so on. Sex proportion leads to low marriage rate, thus lowering fertility rate more, however, the low fertility rate will make aging condition more severe, all of these may lower energy productivity and increase energy consumption. Right now, the most important thing is breaking the energy development restriction which is caused by population problems, and then open up positive circular chains between them.

In China, it's urgent to solve the problems of population and energy, the development pattern which means high input and high consumption has come to the point that must be changed. In order to change the model of population development and energy production-consumption, forming society into a population-energy-economy steady state, it's in an urgent need to take a comprehensive investigation of thinking, strategy, system, policy and line, so that forming a scientific and sustainable development path with Chinese characteristics.

\section{References}

[1] Ministry of Land and Resources of China (2016). China Mineral Resources [M], Beijing, Geological Publishing House, 2016.

[2] National Bureau of Statistics of China (2015). China Energy Statistical Yearbook [M], Beijing, China Statistics Press, 2015.

[3] Meadows D and J. Randers (1972). Limits to Growth [M], Beijing, The Commercial Press, 1984.

[4] Xia, Z. Y. and W. Zhang (2009). An empirical study on the relationship between energy consumption, population and economic growth in China [J], Population \& Economics, 2009, 176(05): 7-12.

[5] Malthus T. R. An Essay on the Principle of Population [M], Zhu, Y. and Q.L. Hu, Translate, Beijing, The Commercial Press, 1992.

[6] Zhang Lei and G. T. Cai (2005). Discussion on population development and energy supply security in China [J], Beijing, China Soft Science, 2005(11): 11-17.

[7] Liu, S. Y (1985). Population and Energy [J], Population \& Economics, 1985(2): 27-31. 